\title{
DIRECTIONS OF COLOUR CHANGES OF NECTAR HONEYS DEPENDING ON HONEY TYPE AND STORAGE CONDITIONS
}

\author{
Alina Piotraszewska-Pająk \\ Anna Gliszczyńska-Świgło* \\ Poznań University of Economics, Faculty of Commodity Science, \\ al. Niepodległosci 10, 61-875 Poznań, Poland \\ *corresponding author: a.gliszczynska-swiglo@ue.poznan.pl \\ Received 11 December 2014; accepted 24 July 2015
}

\section{A bstract}

The colour of honey is one of the most important quality criteria for consumers. The colour depends mainly on the content of plant pigments but the honey consistency, shape, and size of the crystals may also influence the honey colour parameters. It is related to the crystallisation and decrystallisation processes of honey during storage. In the present study, directions of colour changes of honey during storage were evaluated using a tristimulus colorimeter and the CIE $1976 L^{*} a^{*} b^{*}$ and CIE $L^{*} C^{*} h^{\circ}$ systems. The effect of time ( 3 and 9 months) and storage conditions (cold storage, room temperature storage with access to light, and room temperature storage without access to light) on the colour of nectar honeys was investigated. The results obtained showed that both the type of honey and the storage conditions influenced the honey colour parameters. Significant differences in direction and intensity of the colour changes of honey during storage were observed. These differences make it difficult to indicate which storage conditions are optimal to preserve the colour of the honey. It was found that acacia and heather honeys were the most susceptible to colour changes during long-term storage in all of the study's applied conditions, whereas rape and buckwheat honeys were the most stable in colour parameters.

Keywords: CIE $L^{*} a^{*} b^{\star}, C I E ~ L * C * h^{\circ}$, colour characteristics, nectar honey storage, tristimulus colorimeter.

\section{INTRODUCTION}

Honeys are seasonal products of different botanical and geographical origin. Due to seasonal and environmental factors, they contain different contents of carbohydrates, volatile compounds, vitamins, minerals, phytochemicals, and others. Their physical properties such as $\mathrm{pH}$, acidity, viscosity, electrical conductivity, and colour are also dependent on the type of honey. Moreover, processing (e.g. filtration and heating) and storage have an effect on honey composition and properties (White, 1976; 1978; Wang et al., 2004; Turkmen et al., 2006).

The aroma, flavour, and colour of honey are important quality criteria of this product. These three factors may serve as indicators of the plant source. Colour of honey may range from very pale yellow, amber, dark reddish amber to nearly black (Negueruela and Perez-Arquillue, 2000; Terrab et al., 2004; Bertoncelj et al., 2007). This is the result of a type of floral nectar and it is mainly related to the presence of carotenoids, chlorophylls, plant phenolic compounds, and Maillard reaction products (White, 1978; Belitz et al., 2004). Terrab et al. (2004) showed that pollen grains present in honey also have an effect on the colour. Moreover, Balbarrey et al. (2012) reported that a dark colour of honey is closely related to the mineral content.

Although colour parameters, i.e. lightness, hue, and chroma, are not included in the honey quality control system, many producers, distributors, and consumers may be interested in honey colour and the colour changes that may take place while the honey is stored. Honeydew honeys and dark nectar honeys (dark multifloral, buckwheat, heather) were reported to have higher antibacterial activity towards Staphylococcus aureus and Escherichia coli than light nectar honeys (acacia, linden and rape) (Piotraszewska-Pająk et al., 2005). It was also established, that long-term storage of honeys at room temperature in the dark resulted in Bacillus subtilis resistance to antibacterial action of honeys and a partial loss of Escherichia coli sensitivity. This loss of honey antibacterial activity coincided with 
the changes in colour and formation of melanoids (Brudzynski and Kim, 2011). Moreover, the correlation between the colour of different honeys and the antioxidant activities of the honeys were also found. This finding provides a good indicator for consumers looking for products with the highest antioxidant capacity (Zalibera et al., 2008).

The first aim of the present study was to characterise the colour of nectar honeys in their solid state. The second aim was to characterise the colour changes in time and during different storage conditions of honeys. Previous studies concerning colour of honeys refered mostly to the colour of honey after the honey was heated to $40-50^{\circ} \mathrm{C}$ to dissolve the sugar crystals (Gonzales et al., 1999; Terrab et al., 2003a, b, c; Bertoncelj et al., 2007; Ferreira et al., 2009; Gallez et al., 2012). Some authors of these studies claimed that this process did not alter the honey colour but they did not quote any results to confirm their claims. Our preliminary results showed that heating honey up to $42^{\circ} \mathrm{C}$ to dissolve the sugar crystals (about 3 hours) may significantly change colour parameters of some types of honey. Other physicochemical parameters of honeys satisfied the quality criteria of honeys specified by the EC Directive 2001/110 (EU, 2001). We particularly observed the changes in lightness and the contribution of yellow colour. Depending on honey type, the $L^{*}$ and $b^{*}$ values of liquid honey may be 1.5 - 10 and 2 - 6 units lower than that of solid honey, respectively. Therefore, the consistency and the shape and size of the crystals may influence the colour parameters of honey, especially during storage when crystallisation and decrystallisation of honey may occur (White, 1976; Negueruela and Perez-Arquillue, 2000). The literature data on the influence of long-term storage at different conditions, on colour of nectar honeys, are limited and sometimes contradictory. The results of the previous study by Piotraszewska-Pająk (2012) revealed that long-term storage of rape and heather honeys at room temperature significantly influenced the colour parameters of honeys. Moreover, it was observed that there was an essential difference in direction and intensity of colour changes depending on an access to light during storage. The present study was extended to include storage of rape and heather honeys in the cold. Other nectar honeys (acacia, linden, multifloral, and buckwheat) were included and stored both in the cold and at room temperatures. To the best of our knowledge, there are no studies comparing the colour changes of honeys stored in the cold and at room temperature with and without access to light.

\section{MATERIAL AND METHODS}

\section{Material}

Eighteen samples of non-standardised honeys of six botanical origin: four light types - rape (Brassica napus), acacia (Robinia pseudoacacia), linden (Tilia spp.), multifloral (nectar honey from different plants), and two dark types - heather (Calluna vulgaris) and buckwheat (Fagopyrum esculentum Möench), were investigated. All honeys were bought directly from official institutions or professional Polish beekeepers with a guaranteed type, origin, and known history. It means that the type and origin of honey was confirmed by the sensory and physicochemical analyses according to the EC Directive 2001/110 (EU, 2001) and Polish Norm PN88/A-77626 (1988). The samples originated from 15 different producers located in different regions of Poland. Honeys were extracted by centrifugation and all were crude (i.e., without any heating treatments). Each type of honey was divided into four groups: fresh honeys, stored in the cold (approximately $4-6^{\circ} \mathrm{C}$ ), stored at room temperature (approximately $22-24^{\circ} \mathrm{C}$ ) with access to light, and stored at room temperature in the dark. The colour of all fresh and stored honeys was measured after 3 and 9 months. The results obtained for fresh rape and heather honeys as well as for rape and heather honeys stored at room temperature have been already published (Piotraszewska-Pająk, 2012). Before analysis, all honeys stored in the cold had been kept at room temperature to equalise the temperature of all honey samples.

\section{Methods}

The colour of honeys was determined in the the CIE $1976 L^{*} a^{*} b^{*}$ and $L^{*} C^{*} h^{\circ}$ systems. The $L^{*}$ describes the lightness, a* indicates the intensity of red colour in the positive range and the green one in the negative range, $b^{\star}$ value indicates the intensity of yellow colour in the positive range and the blue one in the negative range. Moreover, metric chroma $\left(C^{\star}\right)$, hue angle $\left(h^{\circ}\right)$ as well as the lightness difference $\left(\Delta L^{*}\right)$, chroma difference $\left(\Delta C^{*}\right)$, metric hue difference $\left(\Delta \mathrm{H}^{\star}\right)$, and total colour difference $\left(\Delta \mathrm{E}^{*}{ }_{\mathrm{ab}}\right)$ between the values corresponding to the stored (s) and fresh (f) samples were calculated using the following equations:

$C^{*}=\left[\left(a^{*}\right)^{2}+\left(b^{\star}\right)^{2}\right]^{1 / 2}$, $h^{0}=\operatorname{tg}^{-1}\left(b^{*} / a^{*}\right)$, when $a^{*}>0$ and $b^{*} \geq 0$, $h^{0}=180^{\circ}+\operatorname{tg}^{-1}\left(b^{*} / a^{*}\right)$, when $a^{*}<0$.

$\Delta L^{*}=L_{s}^{*}-L_{f}^{*}$ 
$\Delta \mathrm{C}^{*}=\mathrm{C}^{*}{ }_{\mathrm{s}}-\mathrm{C}_{\mathrm{f}}^{*}=\left[\left(\mathrm{a}_{\mathrm{s}}{ }^{*}\right)^{2}+\left(\mathrm{b}_{\mathrm{s}}{ }^{*}\right)^{2}\right]^{1 / 2}-\left[\left(\mathrm{a}_{\mathrm{f}}{ }^{*}\right)^{2}+\left(\mathrm{b}_{\mathrm{f}}{ }^{*}\right)^{2}\right]^{1 / 2}$

A positive value indicates a higher lightness or chroma of a stored sample than that of a fresh one. A negative value indicates lower lightness or chroma of a stored sample than that of a fresh one.

$\left.\Delta H^{*}=\left[\Delta E^{*}{ }_{a b}\right)-\left(\Delta L^{*}\right)^{2}-\left(\Delta C^{\star}\right)^{2}\right]^{1 / 2}$,

$\Delta \mathrm{E}_{\mathrm{ab}}{ }^{*}=\left[\left(\Delta \mathrm{L}^{*}\right)^{2}-\left(\Delta \mathrm{a}^{*}\right)^{2}-\left(\Delta \mathrm{b}^{*}\right)^{2}\right]^{1 / 2}$,

where: $\Delta a^{*}=a_{s}^{*}-a_{f}^{*}$ and $\Delta b^{*}=b_{s}^{*}-b_{f}^{*}$.

All colour functions were calculated for illuminant $\mathrm{D}_{65}$ and the $2^{\circ}$ angle observer through the tristimulus values obtained using Minolta Chroma Meter CR310 (Konica Minolta) offering a $50 \mathrm{~mm}$ diameter measuring area, and wide-area illumination $/ 0^{\circ}$ viewing geometry. The honey samples in the solid state were thoroughly stirred and placed in Granular-Materials Attachment CR-A50 (Konica Minolta) and covered with a quartz plate. For each honey sample, nine measurements were performed.

\section{Statistical analysis}

Data are presented as the average \pm SD of three honeys of the same type originated from three different producers. One-way analysis of variance (ANOVA) was performed to determine the significance of differences between the colour parameters of the fresh honeys. The significance of differences between the colour parameters of the fresh honeys was evaluated using the Tukey's test. Three-way analysis of variance was performed to evaluate the effects of honey type, time, and temperature of storage, on colour parameters of the honeys. The significance of differences between the fresh and stored honeys was evaluated by the Dunnett's test using fresh honey samples as the control. Pearson's correlation coefficients were also calculated to determine the possible association between $L^{*}, C^{*}$, and $h^{\circ}$ values of fresh honeys and $L^{*}, C^{*}$, and $h^{\circ}$ values of stored honeys. Statistical analyses were performed using Statistica version 9.0 at 5\% level of significance.

\section{RESULTS}

Colour parameters of the fresh nectar honeys from our present study are presented in Table 1. The average results obtained in the previous study by Piotraszewska-Pająk (2012) for fresh rape and heather honeys stored at room temperature were also included, to be able to compare the effect of time and access to light on the colour of different nectar honeys.

Statistical analysis revealed that the fresh nectar honeys tested were not significantly different in $L^{*}$, $\mathrm{b}^{*}$ and $\mathrm{C}^{*}$ values but light nectar honeys (rape, acacia, linden, and multifloral) differed from dark nectar honeys (heather and buckwheat) in their contribution of green/red colour $\left(a^{\star}\right)$ and hue angle $\left(h^{\circ}\right)$. It was also observed that fresh acacia, multifloral, and heather honeys, originating from different regions of Poland, were significantly different in lightness (standard deviation of the average $L^{*}$ values was relatively high; Tab. 1). This finding was related to the differences in consistency which have a crucial influence on honey lightness. During storage, the honey crystallised and the lightness became less diversified.

Table 1.

The lightness $\left(L^{\star}\right)$, intensity of red or green colour ( $a^{\star}$, positive and negative values, respectively), intensity of yellow colour ( $\mathrm{b}^{\star}$, positive values), metric chroma $\left(\mathrm{C}^{\star}\right)$ and hue angle $\left(\mathrm{h}^{\circ}\right)$ of fresh nectar honeys

\begin{tabular}{|c|c|c|c|c|c|c|}
\hline $\begin{array}{l}\text { Honey } \\
\text { type }\end{array}$ & Рагаmeter & $L^{*}$ & $a^{\star}$ & $b^{\star}$ & $C^{*}$ & $h^{0}$ \\
\hline \multirow{2}{*}{$\begin{array}{l}\text { Rape } \\
\mathrm{n}=3\end{array}$} & Average $\pm \mathrm{SD}^{1,2}$ & $70.56 \pm 2.70^{a}$ & $-2.08 \pm 0.67^{a}$ & $18.51 \pm 1.35^{a}$ & $18.64 \pm 1.29^{a}$ & $96.85 \pm 2.36^{a}$ \\
\hline & Range & $68.56 \div 73.64$ & $-1.35 \div(-2.65)$ & $17.47 \div 20.04$ & $17.61 \div 20.03$ & $93.86 \div 98.37$ \\
\hline \multirow{2}{*}{$\begin{array}{c}\text { Acacia } \\
\mathrm{n}=3\end{array}$} & Average \pm SD & $53.10 \pm 16.27^{a}$ & $-2.71 \pm 1.61^{a}$ & $9.32 \pm 4.17^{\mathrm{a}}$ & $9.71 \pm 4.43^{\mathrm{a}}$ & $105.13 \pm 4.15^{a}$ \\
\hline & Range & $34.32 \div 62.89$ & $-0.87 \div(-3.85)$ & $4.55 \div 12.26$ & $4.63 \div 2.72$ & $100.82 \div 109.09$ \\
\hline \multirow{2}{*}{$\begin{array}{c}\text { Linden } \\
n=3\end{array}$} & Average \pm SD & $64.27 \pm 5.21^{a}$ & $-3.56 \pm 0.11^{a}$ & $19.12 \pm 1.75^{a}$ & $19.45 \pm 1.72^{\mathrm{a}}$ & $100.60 \pm 1.00^{a}$ \\
\hline & Range & $58.43 \div 68.43$ & $-3.43 \div(-3.63)$ & $17.41 \div 20.91$ & $17.78 \div 1.22$ & $99.85 \div 101.74$ \\
\hline \multirow{2}{*}{$\begin{array}{c}\text { Multifloral } \\
n=3\end{array}$} & Average \pm SD & $60.15 \pm 12.54^{a}$ & $-2.40 \pm 2.18^{\mathrm{a}}$ & $22.89 \pm 8.69^{a}$ & $23.11 \pm 8.60^{\mathrm{a}}$ & $96.90 \pm 5.85^{a}$ \\
\hline & Range & $45.75 \div 68.63$ & $-0.51 \div(-4.79)$ & $15.03 \pm 32.22$ & $15.15 \div 2.22$ & $90.91 \div 102.61$ \\
\hline \multirow{2}{*}{$\begin{array}{c}\text { Heather } \\
n=3\end{array}$} & Average $\pm \mathrm{SD}^{2}$ & $49.62 \pm 14.79^{a}$ & $2.38 \pm 1.84^{b}$ & $25.19 \pm 12.36^{a}$ & $25.33 \pm 12.43^{a}$ & $84.70 \pm 2.63^{b}$ \\
\hline & Range & $33.07 \div 61.53$ & $0.90 \div 4.44$ & $11.01 \div 33.69$ & $11.05 \div 33.74$ & $81.81 \div 86.96$ \\
\hline \multirow{2}{*}{$\begin{array}{c}\text { Buckwheat } \\
n=3\end{array}$} & Average \pm SD & $51.28 \pm 6.38^{a}$ & $6.32 \pm 1.86^{b}$ & $26.62 \pm 3.52^{a}$ & $27.44 \pm 3.00^{\mathrm{a}}$ & $76.24 \pm 5.44^{b}$ \\
\hline & Range & $44.46 \div 57.11$ & $4.39 \div 8.10$ & $23.43 \div 30.39$ & $24.79 \div 0.71$ & $70.91 \div 81.78$ \\
\hline
\end{tabular}

\footnotetext{
${ }^{1} \mathrm{a}, \mathrm{b}$ - the avergaes in the column with the same letters are not significantly different at $\alpha=0.05$.
}

${ }^{2}$ From Piotraszewska-Pająk (2012). 
Table 2.

Average lightness $\left(L^{\star}\right)$, intensity of red or green colour ( $a^{*}$, positive and negative values, respectively), intensity of yellow colour ( $b^{\star}$, positive values), metric chroma $\left(C^{\star}\right)$ and hue angle $\left(h^{\circ}\right)$ values of fresh nectar honeys, stored for 3 and 9 months in different conditions ${ }^{1}$

\begin{tabular}{|c|c|c|c|c|c|c|}
\hline $\begin{array}{l}\text { Honey } \\
\text { type }\end{array}$ & Storage & $L^{*}$ & $a^{*}$ & $b^{\star}$ & $C^{*}$ & $h^{\circ}$ \\
\hline \multirow{7}{*}{$\begin{array}{l}\text { Rape } \\
n=3\end{array}$} & Fresh $^{2}$ & $70.56 \pm 2.70$ & $-2.08 \pm 0.67$ & $18.51 \pm 1.35$ & $18.64 \pm 1.29$ & $96.85 \pm 2.36$ \\
\hline & 3M_cold & $69.93 \pm 2.68$ & $-1.58 \pm 0.66$ & $17.84 \pm 1.51$ & $17.92 \pm 2.04$ & $95.19 \pm 2.53$ \\
\hline & 3M_light ${ }^{2}$ & $81.22 \pm 1.15^{a}$ & $-1.63 \pm 0.58$ & $18.64 \pm$ & $18.72 \pm 1.38$ & $95.05 \pm 1.95$ \\
\hline & 3M_dark ${ }^{2}$ & $67.66 \pm 1.09$ & $-1.30 \pm 0.65$ & $19.47 \pm 1.42$ & $19.52 \pm 1.40$ & $93.88 \pm 2.05$ \\
\hline & 9M_cold & $80.11 \pm 3.09^{a}$ & $1.39 \pm 0.64^{a}$ & $21.11 \pm 1.14$ & $21.16 \pm 1.67$ & $86.30 \pm 1.52^{a}$ \\
\hline & 9M_light ${ }^{2}$ & $65.92 \pm 1.82$ & $-0.49 \pm 0.40^{a}$ & $19.63 \pm 1.29$ & $19.64 \pm 1.28$ & $91.47 \pm 1.27^{a}$ \\
\hline & 9M_dark ${ }^{2}$ & $70.87 \pm 0.91$ & $3.32 \pm 0.38^{a}$ & $25.42 \pm 0.97^{a}$ & $25.64 \pm 0.97^{\circ}$ & $82.56 \pm 0.86^{a}$ \\
\hline \multirow{7}{*}{$\begin{array}{c}\text { Acacia } \\
n=3\end{array}$} & Fresh & $53.10 \pm 16.27$ & $-2.71 \pm 1.61$ & $9.32 \pm 4.17$ & $9.71 \pm 4.43$ & $105.13 \pm 4.15$ \\
\hline & 3M_cold & $60.68 \pm 8.14$ & $-2.88 \pm 0.54$ & $11.53 \pm 1.58$ & $11.89 \pm 1.66$ & $103.96 \pm 1.04$ \\
\hline & 3M_light & $74.25 \pm$ & $-2.83 \pm$ & 12.31 & 12.63 & $102.95 \pm 0.80$ \\
\hline & 3M_dark & $61.36 \pm 2.93$ & $-2.69 \pm 0.11$ & $13.02 \pm 0.26$ & $13.30 \pm 0.23$ & $101.66 \pm 0.67$ \\
\hline & 9M_cold & $75.41 \pm 2.32^{a}$ & $-0.50 \pm 0.38$ & $18.01 \pm 1.02^{\mathrm{a}}$ & $18.02 \pm 1.04^{a}$ & $91.54 \pm 1.12^{a}$ \\
\hline & 9M_light & $60.70 \pm 4.35$ & $-2.12 \pm 0.17$ & $13.50 \pm 0.71^{a}$ & $13.67 \pm 0.72^{a}$ & $98.90 \pm 0.28^{a}$ \\
\hline & 9M_dark & $69.69 \pm 1.03^{a}$ & $0.93 \pm 0.58^{a}$ & $24.42 \pm$ & $24.45 \pm 1.00^{\circ}$ & $87.83 \pm 1.39$ \\
\hline \multirow{7}{*}{$\begin{array}{c}\text { Linden } \\
n=3\end{array}$} & Fresh & $64.27 \pm 5.21$ & $-3.56 \pm 0.11$ & $19.12 \pm 1.75$ & $19.45 \pm 1.72$ & $100.60 \pm 1.00$ \\
\hline & & $71.85=$ & $-3.32=$ & 19.22 & 19.50 & 99.80 \\
\hline & ght & $83.35 \pm$ & $-3.44=$ & 27 & 20.6 & 99.72 \\
\hline & 3M_dark & $68.90 \pm 2.59$ & $-2.96 \pm 0.21$ & 21.21 & 21.42 & $97.95 \pm 0.82^{a}$ \\
\hline & 9M_cold & $80.13 \pm 2.30^{a}$ & $0.23 \pm 0.29$ & $25.22 \pm 1.19^{a}$ & $25.23 \pm 1.19^{a}$ & $89.47 \pm 0.67^{a}$ \\
\hline & 9M_light & $66.32 \pm 4.72$ & $-2.11 \pm$ & $20.86 \pm 1.97$ & $20.97 \pm 1.94$ & $95.85 \pm 1.27^{a}$ \\
\hline & 9M_dark & $74.44 \pm 6.38^{a}$ & $2.02 \pm 0.68^{a}$ & 28.40 & $28.48=$ & $85.95 \pm 1.17^{a}$ \\
\hline \multirow{7}{*}{$\begin{array}{c}\text { Multifloral } \\
n=3\end{array}$} & Fresh & $60.15 \pm 12.54$ & $-2.40 \pm 2.18$ & 22.89 & $23.11 \pm 8.60$ & $96.90 \pm 5.85$ \\
\hline & & 26 & -1.78 & 22.12 & 22.2 & 4.71 \\
\hline & 3M_light & $74.30=$ & -1.54 & 24.1 & 24.1 & 4.24 \\
\hline & 3M_dark & $61.49 \pm 5.88$ & $-1.26 \pm 2.25$ & $25.15 \pm 6.82$ & $25.26 \pm 6.77$ & $94.39 \pm 4.22$ \\
\hline & 9M_cold & $70.46 \pm 5.61$ & $2.02 \pm 1.56$ & $29.39 \pm 3.20$ & $29.48 \pm 3.27$ & $86.20 \pm 2.78$ \\
\hline & 9M_light & $60.90 \pm 5.45$ & $0.12 \pm 2.31$ & $24.01 \pm 6.17$ & $24.08 \pm 6.20$ & $90.36 \pm 5.17$ \\
\hline & 9M_dark & $67.08 \pm 3.07$ & $5.03 \pm 2.55^{\mathrm{a}}$ & $32.20 \pm 3.86$ & $32.64 \pm 4.03$ & $81.25 \pm 4.02^{\mathrm{a}}$ \\
\hline \multirow{7}{*}{$\begin{array}{c}\text { Heather } \\
n=3\end{array}$} & Fresh $^{2}$ & $49.62 \pm 14.79$ & $2.38 \pm 1.84$ & $25.19 \pm 12.36$ & $25.33 \pm 12.43$ & $84.70 \pm 2.63$ \\
\hline & & & 1.6 & 28.28 & 28.33 & 86.68 \\
\hline & 3M_light ${ }^{2}$ & $68.72 \pm 3.22^{a}$ & $4.47 \pm$ & 32.36 & 32.69 & $82.20 \pm 2.18$ \\
\hline & 3M_dark ${ }^{2}$ & $53.79 \pm 3.40$ & $5.10 \pm 1.66$ & & $31.87 \pm 3.70$ & $80.80 \pm 2.66$ \\
\hline & 9M_cold & $68.26 \pm 5.49^{a}$ & $6.20 \pm 1.31^{a}$ & 30.55 & $31.19 \pm 1.18$ & $78.53 \pm 2.37^{a}$ \\
\hline & 9M_light ${ }^{2}$ & $65.01 \pm 3.12^{\mathrm{a}}$ & $7.80 \pm 1.28$ & 31.51 & 32.47 & $76.16 \pm 1.74^{a}$ \\
\hline & 9M_dark ${ }^{2}$ & $57.79 \pm 2.04$ & $11.16 \pm 0.23^{a}$ & $32.40 \pm 1.70$ & $34.27 \pm 1.69$ & $70.98 \pm 0.56^{a}$ \\
\hline \multirow{7}{*}{$\begin{array}{c}\text { Buckwheat } \\
n=3\end{array}$} & Fresh & $51.28 \pm 6.38$ & $6.32 \pm 1.86$ & $26.62 \pm 3.52$ & $27.44 \pm 3.00$ & $76.24 \pm 5.44$ \\
\hline & 3M_cold & $50.07 \pm 5.32$ & $6.44 \pm$ & $25.67 \pm$ & $26.51 \pm 3.37$ & $75.61 \pm 4.11$ \\
\hline & 3M_light & $57.59 \pm 4.07$ & $8.38 \pm 0.78$ & $27.31 \pm 2.89$ & $28.59 \pm 2.53$ & $72.74 \pm 3.26$ \\
\hline & 3M_dark & $43.66 \pm 5.15$ & $8.32 \pm 0.35$ & $23.36 \pm 5.33$ & $24.86 \pm 4.87$ & $69.71 \pm 5.35$ \\
\hline & 9M_cold & $58.00 \pm$ & $8.54 \pm 1.24^{\mathrm{a}}$ & 26.61 & $28.00 \pm 3.03$ & $71.93 \pm 4.48$ \\
\hline & & & $10.15 \pm 0.33^{a}$ & & $24.33 \pm 2.34$ & $65.16 \pm 2.90$ \\
\hline & 9M_dark & $44.07 \pm 5.14$ & $10.90 \pm 0.88^{a}$ & $19.05 \pm 5.52$ & $22.02 \pm 5.13$ & $59.27 \pm 6.30^{a}$ \\
\hline
\end{tabular}

1 For each honey type, "a" letter in the column indicates stored honeys which are significantly different from appropriate fresh honeys used as the control samples (Dunnett test, $\mathrm{p}<0.05$ ).

${ }^{2}$ From Piotraszewska-Pająk (2012). 


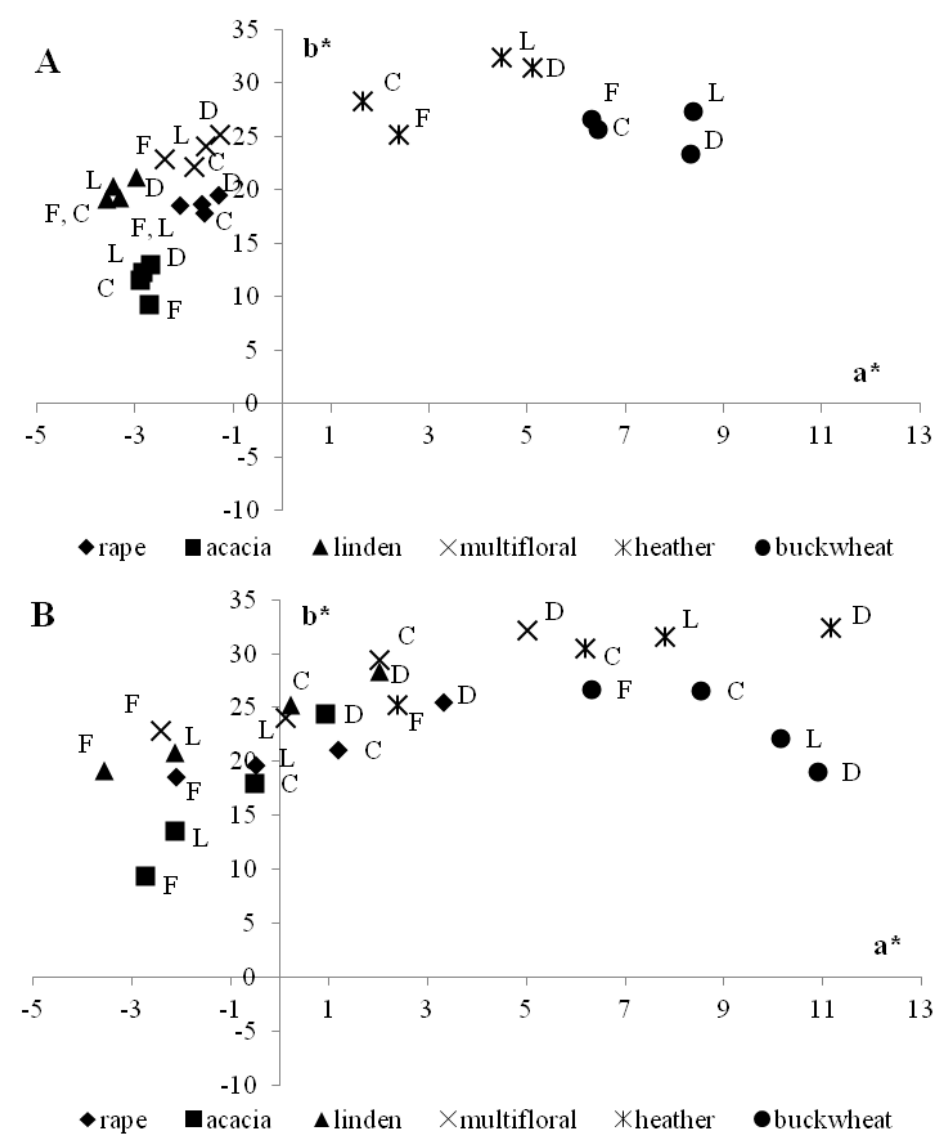

Fig. 1. The changes in the intensity of red or green colour (a*, positive and negative values, respectively), intensity of yellow colour ( $b^{*}$, positive values) values of fresh honeys $(F)$, stored in the cold $(C)$, at room temperature with the access to light $(L)$, and at room temperature in the dark (D) after 3 months (A) and 9 months of storage (B).

Table 3.

Results of three-way analysis of variance ( $F$ and $p$ values)

\begin{tabular}{|c|c|c|c|}
\hline $\begin{array}{c}\text { Colour } \\
\text { parameter }\end{array}$ & Source of variation & F value & p value \\
\hline \multirow{7}{*}{$L^{*}$} & Type of honey & 36.64 & 0.000 \\
\hline & Time & 0.30 & 0.585 \\
\hline & Temperature & 10.64 & 0.000 \\
\hline & Type $x$ time & 0.35 & 0.880 \\
\hline & Type $\mathrm{x}$ temperature & 0.97 & 0.475 \\
\hline & Time $\mathrm{x}$ temperature & 33.77 & 0.000 \\
\hline & Type $\mathrm{x}$ time $\mathrm{x}$ temperature & 0.78 & 0.650 \\
\hline \multirow{7}{*}{$C^{*}$} & Type of honey & 41.82 & 0.000 \\
\hline & Time & 18.01 & 0.000 \\
\hline & Temperature & 4.66 & 0.012 \\
\hline & Type $x$ time & 2.54 & 0.034 \\
\hline & Type $\mathrm{x}$ temperature & 1.55 & 0.137 \\
\hline & Time $x$ temperature & 5.77 & 0.004 \\
\hline & Type $\mathrm{x}$ time $\mathrm{x}$ temperature & 0.42 & 0.935 \\
\hline \multirow{7}{*}{$\mathrm{h}^{0}$} & type of honey & 247.50 & 0.000 \\
\hline & Time & 212.76 & 0.000 \\
\hline & Temperature & 29.32 & 0.000 \\
\hline & Type $x$ time & 0.48 & 0.793 \\
\hline & Type $\mathrm{x}$ temperature & 2.39 & 0.015 \\
\hline & Time $x$ temperature & 12.07 & 0.000 \\
\hline & Type $\mathrm{x}$ time $\mathrm{x}$ temperature & 0.88 & 0.558 \\
\hline
\end{tabular}

$L^{*}$ - lightness; $C^{*}$ - metric chroma; $h^{\circ}$ - hue angle. 


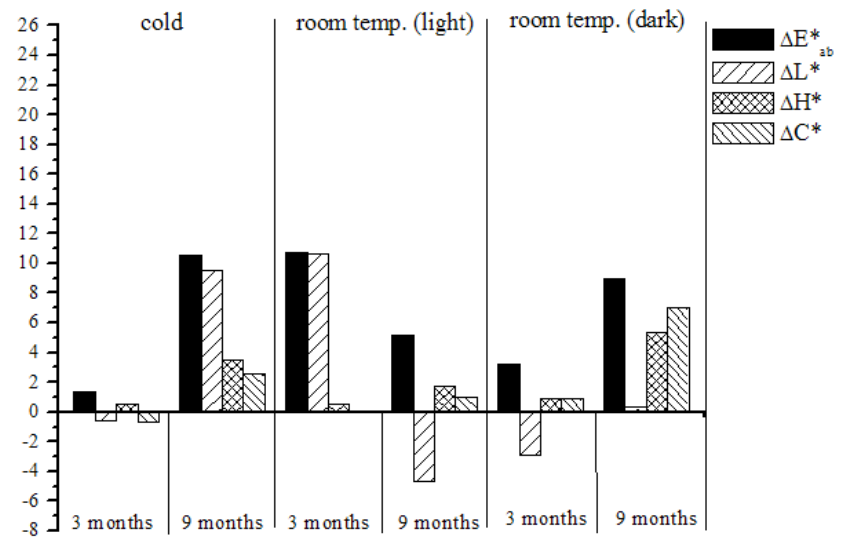

Rape honeys

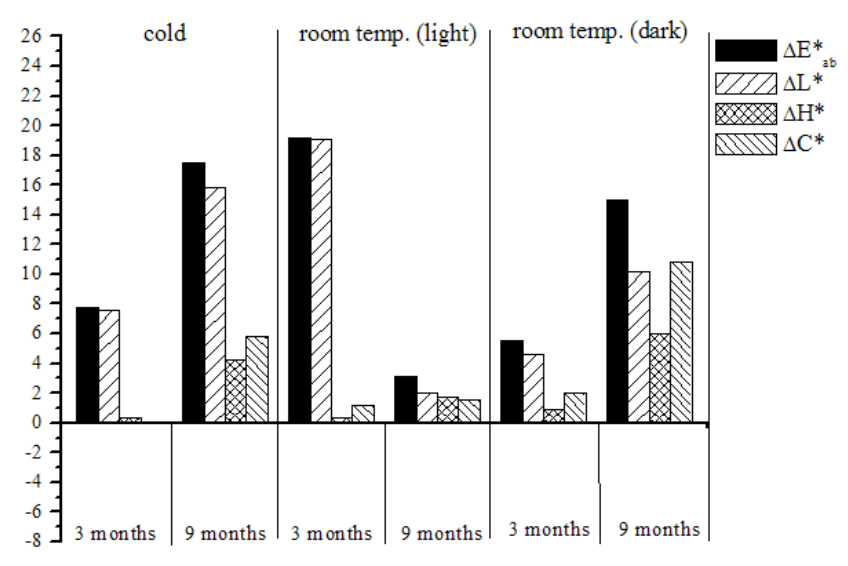

Linden honeys

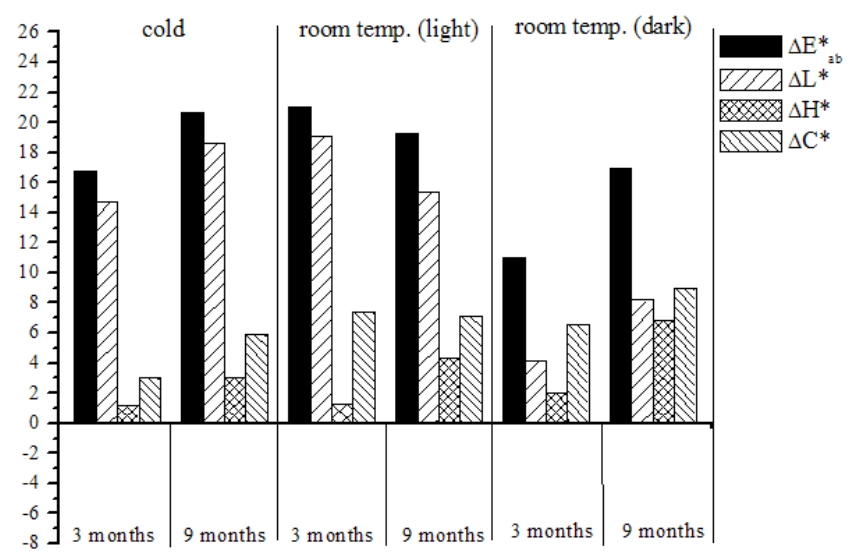

Heather honeys

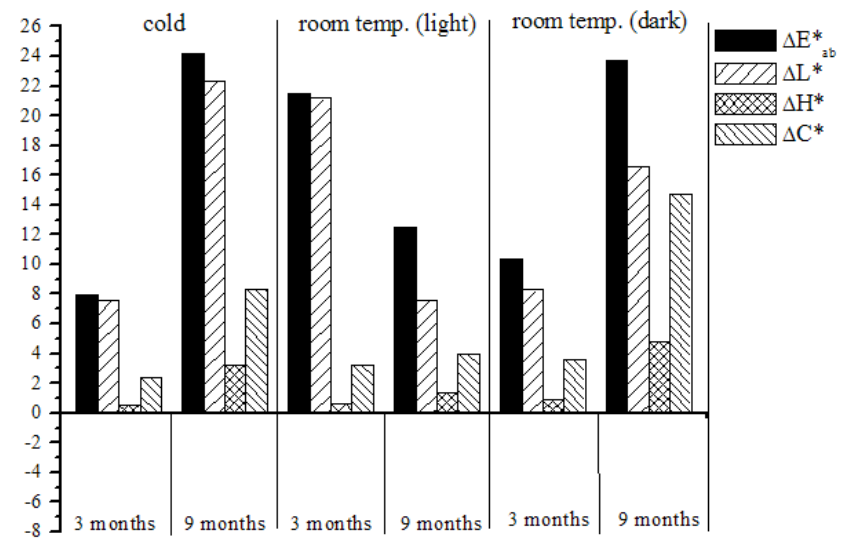

Acacia honeys

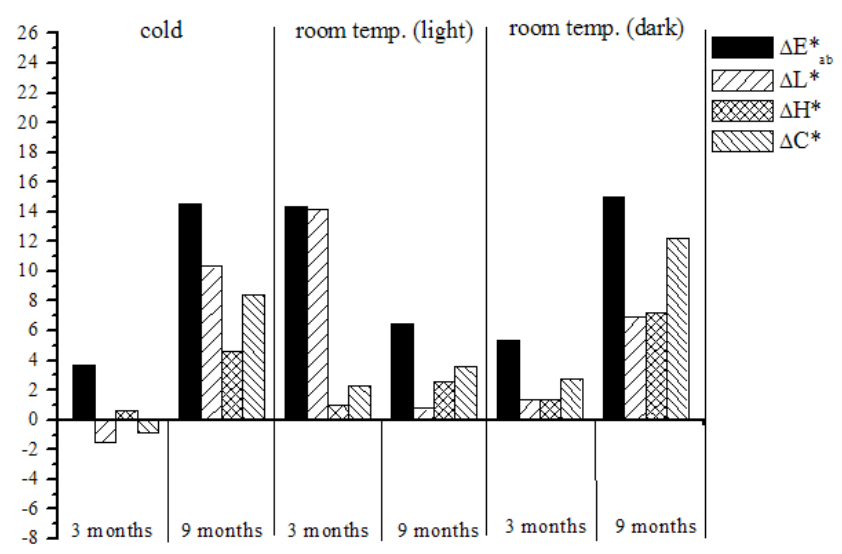

Multifloral honeys

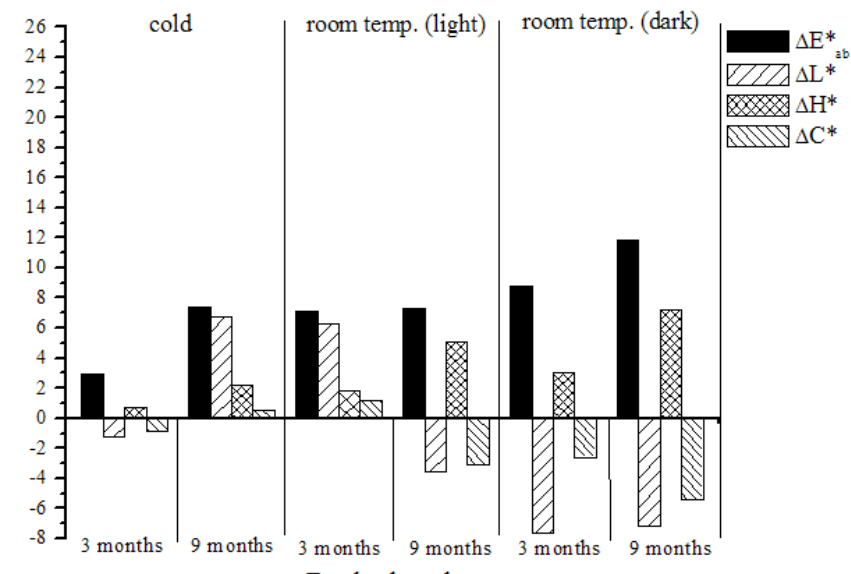

Buckwheat honeys

Fig. 2. Total colour differences $\left(\Delta \mathrm{E}^{*}{ }_{a b}\right)$, differences of lightness $\left(\Delta \mathrm{L}^{*}\right)$, chroma $\left(\Delta \mathrm{C}^{\star}\right)$, and metric hue $\left(\Delta \mathrm{H}^{*}\right)$ of stored honeys. 
All honeys used in the study were stored for 3 and 9 months in the cold, and at room temperature, with and without access to light. The colour parameters of rape and heather honeys stored at room temperature (Piotraszewska-Pająk, 2012) were also included in Table 2. The inclusion was done to have a general view of the changes in the colour of different nectar honeys during storage at room temperature. In Table 2 , the average $L^{*}, a^{*}, b^{*}, C^{*}$, and $h^{\circ}$ values of fresh nectar honeys and stored for 3 and 9 months in different conditions are presented. Three-way analysis of variance revealed that type of honey, time, and temperature of storage had a significant influence on the colour parameters of stored honey (Tab. 3). In Figure 1, the $a^{*}$, and $b^{*}$ values of the fresh and stored honeys are presented to show the direction and intensity of chromaticity changes during storage.

The differences in the colour parameters $\left(\Delta L^{*}, \Delta H^{*}\right.$, $\left.\Delta \mathrm{C}^{\star}\right)$ as well as total colour $\left(\Delta \mathrm{E}^{*}{ }_{\mathrm{ab}}\right)$ differences for honey during storage were calculated to show the changes in all colour parameters (Fig. 2). Moreover, correlation coefficients for linear regression between $L^{*}, C^{*}$, and $h^{\circ}$ values of fresh and stored honeys were calculated to find out whether the final colour parameters of the honeys were related to the initial ones (Tab. 4).
The a* parameter for the fresh honeys had both negative and positive values (Tab. 1). Light nectar honeys (rape, acacia, linden, and multifloral) had a similar contribution of green colour (negative $a^{*}$ value indicating a contribution of green colour pigments such as, e.g. chlorophylls); average a* values ranged from -3.56 to -2.08 . The wide range of $a^{*}$ values for acacia and multifloral honeys indicated considerable differences between the samples of the same type of honey but a contribution of red colour was not observed (Tab. 1). In the dark nectar honeys (heather and buckwheat), the contribution of red colour (positive $a^{\star}$ value), characteristic for anthocyanins and other flavonoids present in plant nectars, was observed (Piotraszewska-Pająk and Ciszak, 2001; Alvarez-Suarez et al., 2010).

For all types of honeys, the $b^{*}$ parameter had positive values indicating the domination of yellow pigments e.g. carotenoids present in plant nectars. It was reported that dark honeys are especially rich in carotenoids (Alvarez-Suarez et al., 2010). Similar observations were done by Bertoncelj et al. (2007) for Slovenian honeys. Although, the light nectar honeys differed from the dark nectar honeys in $a^{*}$ values, the contribution of $a^{*}$ to $C^{*}$ values was small. Therefore, no statistically significant differences in $C^{*}$ values between the light and dark honeys were observed.

Table 4.

Correlation coefficients for the linear regression between the colour parameters of fresh and stored honeys ( $n=18$ )

\begin{tabular}{|c|c|c|c|c|}
\hline $\begin{array}{c}\text { Colour } \\
\text { parameter }\end{array}$ & $\begin{array}{l}\text { Time and storage } \\
\text { conditions }\end{array}$ & Cold & $\begin{array}{c}\text { Room temperature } \\
\text { where light was } \\
\text { present }\end{array}$ & $\begin{array}{c}\text { Room temperature } \\
\text { in the dark }\end{array}$ \\
\hline \multirow{2}{*}{$L_{\text {fresh }}^{*} / L_{\text {stored }}^{*}$} & 3 months & 0.668 & 0.684 & 0.684 \\
\hline & 9 months & 0.541 & $0.411^{a}$ & 0.546 \\
\hline \multirow{2}{*}{$\mathrm{C}_{\text {fresh }}^{*} / \mathrm{C}^{*}{ }_{\text {stored }}$} & 3 months & 0.859 & 0.814 & 0.823 \\
\hline & 9 months & 0.747 & 0.755 & $0.389^{a}$ \\
\hline \multirow{2}{*}{$\mathrm{h}_{\text {fresh }}^{\mathrm{o}} / \mathrm{h}_{\text {stored }}^{\mathrm{o}}$} & 3 months & 0.975 & 0.985 & 0.981 \\
\hline & 9 months & 0.972 & 0.974 & 0.961 \\
\hline
\end{tabular}

a Statistically insignificant $(\alpha=0.05) ; L^{*}$ - lightness; $C^{\star}$ - metric chroma; $h^{\circ}$ - hue angle.

\section{DISCUSSION}

\section{Colour parameters of fresh honeys}

The obtained results revealed that light nectar honeys (rape, acacia, linden, and multifloral) differed from dark nectar honeys (heather and buckwheat) in their contribution of green/red colour ( $\left.a^{\star}\right)$ and hue angle $\left(h^{\circ}\right)$.
For light nectar honeys, hue angle $h^{\circ}$ was located in the second quarter of colour space $\left(h^{\circ}\right.$ higher than $90^{\circ}$ ), whereas for dark nectar honeys - in the first one ( $h^{\circ}$ lower than $90^{\circ}$ ).

For the acacia and linden honeys in the present study, $L^{*}$ and $a^{*}$ values were generally similar to those reported by Bertoncelj et al. (2011), but b* was much lower. They showed that the $b^{*}$ value of 
Slovenian honeys may range from 6.26 to 31.70 for acacia honeys, and from 19.34 to 41.13 for linden honeys. In contrast to Slovenian multifloral honeys (a* ranged from -3.30 to 5.77), no contribution of red colour (positive a* values) was observed for the honeys in this study. Moreover, the contribution of yellow colour in Polish multifloral honeys was also lower than reported by Bertoncelj et al. (2011).

\section{Changes of lightness $\left(L^{*}\right)$ of honey during storage} It was found, that the lightness of multifloral and buckwheat honeys did not significantly change during the whole period of storage in all of the applied conditions used in the study (Tab. 2).

The average lightness of all the tested honeys stored in the cold for 3 months, was not significantly changed. The lightness of rape, acacia, linden, and heather honeys increased significantly during 9 months of storage. It is known that low temperatures encourage crystallisation of honey and this process leads to the increased lightness of this product.

The $L^{*}$ values of the tested honeys, with the exception of multifloral and buckwheat honeys, stored at room temperature in the light for 3 months, significantly increased in comparison with fresh honeys. However, between the third and the ninth month of storage, the lightness of the heather honey no longer changed, and for rape, acacia, and linden honeys, $L^{*}$ decreased to the values similar to the fresh honeys.

The storage of the honeys at room temperature in the dark for 3 and 9 months did not significantly influence their lightness, with the exception of the acacia and linden honeys for which the $L^{*}$ values significantly increased during 9 months of storage (Tab. 2).

It was also observed that access to light during the storage of the honeys at room temperature for 3 months, had a higher effect on the changes in lightness than changes observed during storage of honeys in the dark. Moreover, there were differences in the direction of lightness changes between the third and the ninth month of storage. Generally, the $L^{*}$ of honeys stored in the dark increased, whereas the $L^{*}$ of honeys stored with access to light - decreased.

The effect of exposure to light on honey crystallisation at room temperature was studied by Tchoumboue et al. (2007). They observed complete crystallisation of honeys stored in the darkness at $21-22^{\circ} \mathrm{C}$ for 60 days, whereas for honeys stored under constant light, complete crystallisation did not occur. The effect of light was not clear but they suggested that dark conditions during storage affect physical and chemical factors stimulating granulation or enzymatic formation of monohydrate glucose crystal seeds for crystal growth. In the present study, the increase of lightness between the third and the ninth month of storage was observed for honeys stored in the dark, whereas the $L$ * of honeys stored with access to light - decreased (Tab. 2). Our observations seem to be consistant with the observations of Tchoumboue et al. (2007) related to the crystallisation of honeys. This effect may also explain more visible brightening of all honeys, especially heather honeys, stored for 9 months in the cold, at room temperature with access to daylight, than for the honeys stored at room temperature in the darkness (Fig. 2).

\section{The changes of chromaticity coordinates ( $a^{*}$ and $\left.b^{\star}\right)$, chroma $\left(C^{\star}\right)$, and hue $\left(h^{\circ}\right)$ of honeys during storage}

The $a^{*}, b^{*}$, and $C^{*}$ values (Fig. 1A, Tab. 2) of all tested honeys stored in all the study's conditions, for 3 months, were not significantly changed. Similar results were obtained for $h^{\circ}$ values with the exception of linden honeys stored at room temperature in the dark, for which hue angle slightly decreased in comparison with the fresh honeys (Tab. 2). A significant decrease of hue was observed for rape, acacia, linden, and heather honeys stored in all conditions for 9 months. For multifloral and buckwheat honeys this effect was only observed upon storage at room temperature in the dark. It was also found that, in these conditions, the decrease in $h^{\circ}$ values of all honeys was the highest.

For all honeys stored in all of the applied conditions for 9 months, a* parameter was shifted to the higher values (to the redness) (Fig. 1B). However, a statistically significant increase was observed for rape, linden, heather, and buckwheat honeys stored in all applied conditions, whereas for acacia and multifloral honeys, this effect was observed only during storage at room temperature in the dark (Tab. 2). It is worth noticing, that the influence of storage at room temperature in the dark on $a^{*}$ changes, was the most evident (Fig. 1B).

Values of $b^{*}$ (contribution of yellow colour) were not significantly changed for multifloral, heather, and buckwheat honeys stored for 3 and 9 months in all of the conditions. The most susceptible for $b^{*}$ changes under long-term storage were acacia honeys that were stored in all of the applied conditions. Their average $b^{*}$ value increased about 
4 - 15 units depending on the storage conditions. The contribution of yellow colour was also increased for rape honeys stored at room temperature in the dark and for linden honeys stored in the cold and at room temperature in the dark (Fig. 1B, Tab. 2).

The changes in $C^{*}$ are the consequences of the changes in $b^{*}$ values. Thus, the direction of $C^{*}$ changes was similar to that observed for the $b^{*}$ values. The changes in $b^{*}$ values for acacia honeys stored for 9 months in all the conditions used in the study, and for rape and linden honeys stored in the dark (cold storage and room temperature) resulted in a significantly higher saturation of colour when compared to the fresh honeys ( $\Delta C^{*}$ positive) (Fig. 2). Moreover, as for $b^{\star}$ values, it was observed that chroma changes of honeys stored in the cold and at room temperature in the dark were higher than those observed for honeys stored with access to light (Fig. 2).

It is difficult to explain why elimination of light when stored at room temperature had a higher effect on $a^{*}, b^{*}$, or $C^{*}$ changes than access to light. We cannot exclude the possibility that access to light may delay the formation of melanoides and reduce the changes in nectar honey colour, but such an explanation requires further studies.

\section{The changes of total honey colour $\left(\Delta \mathrm{E}^{*}{ }_{\mathrm{ab}}\right)$ during storage}

Taking total colour difference $\left(\Delta E^{\star}{ }_{a b}\right)$ into account it was observed that low temperature and elimination of light may delay colour changes of some honey types stored for up to 3 months (Fig. 2). Acacia and heather honeys seem to be the most susceptible to colour changes in all of the applied conditions. For these types of honeys, total colour changes during a 9-month storage period were related to either the changes of lightness or chroma and hue. The lowest changes in total colour were observed for rape and buckwheat honeys in all of the study's applied conditions (Fig. 2).

The results obtained for honeys stored at room temperature with access to light are generally in agreement with literature data (White, 1978). Brudzynski and Kim (2011) reported a significant increase in honey colour, measured as net absorbance $\left(A_{560}-A_{720}\right)$ after a two-year storage at room temperature, in the dark. In contrast to our results, they observed relatively smaller differences in colour change in light honeys as compared to darker honeys. The results concerning the cold storage of honeys are inconsistent. According to Jimenez et al. (1994), honeys stored in the cold, darkened. On the other hand, White (1976) reported that low-storage temperatures resulted in lightening of honeys due to the faster crystallisation of sugars. Taking lightness into account, the results of the present study, generally confirm the observations of White (1976).

\section{Correlation between colour parameters of fresh and stored honeys}

The correlation coefficients for linear regression between $L^{*}, C^{*}$, and $h^{\circ}$ values of fresh and stored honeys are shown in Table 4. Relatively high correlation coefficients found for $L^{*}{ }_{\text {fresh }} / L^{*}$ stored and $\mathrm{C}^{*}{ }_{\text {fresh }} / \mathrm{C}^{*}$ stored values of samples stored for 3 months in all of the storage conditions, indicate that final lightness and chroma of these honeys is strongly related to the appropriate initial parameters of honeys. After 3 months of storage, other factors than initial lightness and chroma are related to colour parameters of stored honeys (Gonzales et al., 1999). High correlation coefficients for hue angle of honeys stored for 3 and 9 months indicate consistant changes of honey hue when honey was stored.

It is difficult to explain which factors have a crucial influence on honey colour-changes. The changes in the colour of honey when honey is in its solid state may be related to the changes of pigments. A degradation of pigment may lead to a lower saturation of colour. On the other hand, pigments may react with e.g. metal ions which may result in the increase of chromaticity. Moreover, formation of Millard reaction products, especially melanoids, cristallisation and decrystallisation processes of carbohydrates as well as size and shape of crystals may change the perception of honey colour.

From the quality point of view, the colour changes of honeys are important. An unnatural colour of honey may indicate inappropriate technological processes or long-term storage. These factors contribute to the undesirable changes of physicochemical and functional properties of honeys, e.g. formation of HMF and other Millard reaction products (melanoides), enzyme innactivation and attenuation or decline of antimicrobial activity. Therefore, the colour change may be an indicator of lower honey quality. On the other hand, some Millard reaction products contribute to the antioxidant activity of honeys which may be regarded, to some extent, as beneficial (Antony et al., 2002; Brudzynski and Miotto, 2011). 


\section{CONCLUSIONS}

Altogether, the results obtained indicate that both the honey type and the storage conditions influence the colour of these product. It is difficult to indicate which storage conditions are optimal to keep the initial colour of the honey because susceptibility of honeys to colour changes was different depending on the type of honey and the storage conditions. However, low temperature (no light), and elimination of light at room temperature, and storage for up to 3 months may delay $L^{*}$ changes of honeys, especially light honeys. On the other hand, it was also observed that elimination of light when stored at room temperature had a higher effect on $a^{*}, b^{*}$, $C^{*}$, and $h^{\circ}$ changes than access to light. It cannot be excluded that access to light may delay the formation of e.g. melanoides and lower changes in chromaticity and the hue of honeys but this explanation requires further studies. Moreover, there was an essential difference in the direction of colour changes depending on the access to light while the honey was being stored at room temperature.

Based on the results obtained, it was concluded that acacia and heather honeys are the most susceptible to colour changes in all of the study's applied storage conditions, whereas rape and buckwheat honeys are, generally, the most stable in colour.

It is known that the chemical changes in food, including honey, are slowed down in the cold and such conditions are usually recommended for food storage. Crystallisation of honey, which is faster in the cold than at room temperature, is the only physical process that particularly affects the lightness of honey. Cold and dark conditions do not significantly affect the chemical composition and biological properties of food, thus cold storage should be recommended for all types of honey.

\section{REFERENCES}

Alvarez-Suarez J. M., Tulipani S., Díaz D., Estevez Y., Romandini S., Giampieri F., Damiani E., Astolfi P., Bompadre S., Battino M. (2010) Antioxidant and antimicrobial capacity of several monofloral Cuban honeys and their correlation with color, polyphenol content and other chemical compounds. Food and Chemical Toxicology 48(8-9): 24902499.

Antony S. M., Han I. Y., Rieck J. R., Dawson P. L. (2002) Antioxidative effect of Maillard reaction products added to turkey meat during heating by addition of honey. Journal of Food Science 67(5): 1719-1724.
Balbarrey G. P., Andrada A., Echazarreta J., laconis D., Gallez L. (2012) Relationship between mineral content and color in honeys from two ecological regions in Argentina. In: Caivano J. L., Del Pilarrbuera M. (Eds.) Color in Food. Technological and Psychological Aspects. CRC Press, Taylor and Francis Group. Boca Raton: 305-313.

Belitz H.-D., Grosch W., Schieberle P. (2004) Food Chemistry. Springer. Berlin, Heidelberg. 1071 pp.

Bertoncelj J., Dobersek U., Jamnik M., Golob T. (2007) Evaluation of the phenolic content, antioxidant activity and colour of Slovenian honey. Food Chemistry 105(2): 822-828.

Bertoncelj ]., Golob T., Kropf U., Korošec M. (2011) Characterisation of Slovenian honeys on the basis of sensory and physicochemical analysis with a chemometric approach. International Journal of Food Science and Technology 46(8): 1661-1671

Brudzynski K., Kim L. (2011) Storage-induced changes in active components of honey de-regulate its antibacterial activity. Food Chemistry 126(3): 1155-1163.

Brudzynski K., Miotto D. (2011) The recognition of high molecular weight melanoidins as the main components responsible for radical-scavenging capacity of unheated and heat-treated Canadian honeys. Food Chemistry 125(2): 570-575.

EU (2001) Council Directive 2001/110/EU relating to honey. Official Journal of European Community 12.1.2002 L 10/47-52.

Ferreira I. C. F. R. Aires E., Barreira J. C. M., Estevinho L. M. (2009) Antioxidant activity of Portuguese honey samples: Different contributions of the entire honey and phenolic extract. Food Chemistry $114(4)$ : 1438-1443.

Gallez L., Marconi A., Tourn E., Gonzalez-Miret M. L., Heredia F. J. (2012) Color of honeys from the southwestern Pampas region. Relationship between the Pfund color scale and CIELAB coordinates. In: Caivano J. L., Del Pilarrbuera M. (Eds.) Color in Food. Technological and Psychological Aspects. CRC Press. Taylor and Francis Group. Boca Raton: 133-141.

Gonzales A. P., Burin L., Del Pilarbuera M. (1999) Color changes during storage of honeys in relation to their composition and initial color. Food Research International 32(3): 185-191. 
Jimenez M., Mateo J. J., Huerta T., Mateo R. (1994) Influence of storage conditions on some physicochemical and mycological parameters of honey. Journal of the Science of Food and Agriculture 64(1): 67-74.

Negueruela A. I., Perez-Arquillue C. (2000) Color of rosemary honey in the solid state by reflectance spectroscopy with black background. Journal of AOAC International 83(3): 669-674.

Piotraszewska-Pająk A. (2012) The changes of colour of rape and heather honeys during storage. Towaroznawcze Problemy Jakości (Polish Journal of Commodity Science) 3(32): 96-104.

Piotraszewska-Pająk A., Ciszak S. (2001) The influence of botanical origin on sugar composition, acidity and colour of nectar honeys. In: Proceedings of the $13^{\text {th }}$ ICWT Symposium, Commodity Science in Global Quality Perspective. Maribor - Slovenia. 2-8 September 2001: 705-710.

Piotraszewska-Pająk A., Krauze J., Jasińska K. (2005) Antibacterial activity and selected enzymes activities of different honey types. In: Proceedings of the $8^{\text {th }}$ International Commodity Science Conference (IGWT) Current Trends in Commodity Science. Poznań - Poland. 28 August - 4 September 2005: 1155-1161.

PN-88/A-77626 (1988) „Miód Pszczeli”. Dziennik Norm i Miar nr 8. Wydawnictwo Normalizacyjne Alfa. Warszawa.

Statistica ver. 9.0 (2009) StatSoft Inc.

Tchoumboue J., Awah-Ndukum J., Fonteh F.A., Dongock N. D., Pinta J., Mvondo Z. A. (2007) Physico-chemical and microbilogical characteristics of honey from the sudanoguinean zone of West Cameroon. African Journal of Biotechnology 6(7): 908-913.

Terrab A., Diez M. J., Heredia F. J. (2003a) Palynological, physico-chemical and colour characterization of Maroccan honeys. I. River red gum (Eucalyptus camaldulensis Dehnh) honey. International Journal of Food Science and Technology 38(4): 379-386.
Terrab A., Diez M. J., Heredia F. J. (2003b) Palynological, physico-chemical and colour characterization of Maroccan honeys. II. Orange (Citrus sp.) honey. International Journal of Food Science and Technology 38(4): 387-394.

Terrab A., Diez M. J., Heredia F. J. (2003c) Palynological, physico-chemical and colour characterization of Maroccan honeys. III. Other unifloral honey types. International Journal of Food Science and Technology 38(4): 395-402.

Terrab A., Escudero M. L., González-Miret M. L., Heredia F. J. (2004) Colour characteristics of honeys as influenced by pollen grain content: a multivariate study. Journal of the Science of Food and Agriculture 84(4): 380-386.

Turkmen N., Sari F., Poyrazoglu E. S., Velioglu, Y. S. (2006) Effects of prolonged heating on antioxidant activity and colour of honey. Food Chemistry 95(4): 653-657.

Wang X. H., Gheldof N., Engeseth N. J. (2004) Effect of processing and storage on antioxidant capacity of honey. Journal of Food Science 69(2): 96-101.

White J. W. (1976) Physical characteristics of honey. In: Crane E (Ed.) Honey. A Comprehensive Survey. Heinemann. London: 207-239.

White J. W. (1978) Honey. Advances in Food Research 24: 288-344.

Zalibera M., Stasko A., Slebodova A., Jancovicova V., Cermakova T., Brezova V. (2008) Antioxidant and radicalscavenging activities of Slovak honeys - An electron paramagnetic resonance study. Food Chemistry $110(2)$ : 512-521. 